32 Sucksmith E, Allison C, Baron-Cohen S, Chakrabarti B, Hoekstra RA. Empathy and emotion recognition in people with autism, first-degree relatives and controls. Neuropsychologia 2013; 51: 98-105.

33 Tavassoli T, Hoekstra RA, Baron-Cohen S. The Sensory Perception Quotient (SPQ): development and validation of a new sensory questionnaire for adults with and without autism. Mol Autism 2014; 5: 29.

34 Mandy W, Charman T, Puura K, Skuse D. Investigating the cross-cultural validity of DSM-5 autism spectrum disorder: evidence from Finnish and UK samples. Autism 2014; 18: 45-54.

35 Scheeren AM, Stauder JE. Broader autism phenotype in parents of autistic children: Reality or myth? J Autism Dev Disord 2008; 38: 276-87.

36 Greaves-Lord K, Eussen ML, Verhulst FC, Minderaa RB, Mandy W, Hudziak JJ, et al. Empirically based phenotypic profiles of children with pervasive developmental disorders: interpretation in the light of the DSM-5. J Autism Dev Disord 2013: 43: 1784-97.

37 Chakrabarti S, Fombonne E. Pervasive developmental disorders in pre-school children. JAMA 2001: 285: 3093-9.

38 Todd M, Davis KE, Cafferty TP. Who volunteers for adult development research? Research findings and practical steps to reach low volunteering groups. Int J Aging Hum Dev 1983; 18: 177-84.

39 Rosenthal R, Rosnow RL. The Volunteer Subject. John Wiley and Sons 1975.

40 Lee H, Marvin AR, Watson T, Piggot J, Law JK, Law PA. Accuracy of phenotyping of autistic children based on internet implemented parent report. Am J Med Genet 2010; 153: 1119-26. psychiatry in history

\section{How could it happen? The killing of people in mental hospitals in Germany under the Third Reich}

\section{Alistair Stewart}

About 70000 people resident in mental hospitals in Germany were killed by gassing between 1940 and 1941. The number matched a target which had been set previously. This dreadful crime both required, and was facilitated by, a certain bureaucratic procedure. This was described by SS Colonel Viktor Brack under questioning before the Nuremberg Military Court in 1946 (translated from the German by the author).

Q. Do you mean to say these people were gassed in the chambers without any kind of written order? Who signed it?

A. Well Hitler had signed it of course.

Q. Hitler certainly ordered the euthanasia programme, but he never signed an order that, say, Johann Schmidt should undergo euthanasia. Who wrote the order that these people in those particular hospitals should be sent into the gas chambers?

A. There wasn't one single order of that kind, rather it was a consequence or the result of tests and checks corresponding to the wish Hitler expressed in his order ... Johann Schmidt, if I can keep to this name, Johann Schmidt's questionnaire, which was filled out by the hospital doctor at his first hospital A, was sent in three copies to three different expert assessors. In this connection Bouhler had insisted that none of these three assessors should be one of the doctors treating this patient. After their assessment they sent their questionnaires back to No.4 Tiergartenstrasse. There, the assessments of these three doctors were transferred from their three questionnaires on to a fourth questionnaire, once again bearing the name Johann schmidt. The chief assessor then decided whether this Johann Schmidt should be transferred to an observation unit. If he decided he should be transferred to an observation unit, he notified the Ministry of the Interior. The Ministry of the Interior then arranged the transfer of Johann Schmidt from hospital A, where he belonged, into an observation unit. In this observation unit a doctor was tasked with observing these patients. If his observations agreed with the results of the assessments by these assessors and their chief assessor, then the doctor would declare this to No. 4 Tiergartenstrasse on a list, or in other cases the chief assessors would form their own opinion with the doctor while on a visit to his hospital, by examining each individual patient. Then the Ministry of the Interior provided the observation unit with all the details of those patients who were now to be transferred to the euthanasia unit, and to this euthanasia unit a photocopy was sent from No. 4 Tiergartenstrasse with the chief assessor's observation note attached, so that the euthanasia doctor had all the patient's documents to hand, because in the end it was for him alone to decide whether, on the basis of the available assessment documents, he would give this patient a merciful death or not.

Q. So it was he who gave the final order to carry out euthanasia, in respect of Johann Schmidt, or of any other mentally ill person.

A. No, he didn't give any order, rather he carried out the euthanasia.

The court material is cited in Die Toetung Geisteskranker in Deutschland (1948) by Alice Platen-Hallermund, who attended the trials as a young doctor. Her book still awaits an English translation. The current translation is imperfect, but it does not exaggerate the cynicism of the language. 